\title{
Jab1 is overexpressed in human breast cancer and is a downstream target for HER-2/neu
}

\author{
Ming-Chuan $\mathrm{Hsu}^{1}$, Chee-Yin $\mathrm{Chai}^{2,5}$, Ming-Feng Hou ${ }^{3,5}$, Hui-Chiu Chang ${ }^{1,5}$, Wan-Tzu Chen ${ }^{2}$ \\ and Wen-Chun Hung \\ ${ }^{1}$ Graduate Institute of Medicine, College of Medicine, Kaohsiung Medical University, Kaohsiung, Taiwan; \\ ${ }^{2}$ Department of Pathology, College of Medicine, Kaohsiung Medical University, Kaohsiung, Taiwan; \\ ${ }^{3}$ Department of Surgery, Kaohsiung Medical University, Kaohsiung, Taiwan; ${ }^{4}$ Institute of Biomedical \\ Sciences, National Sun Yat-Sen University, Kaohsiung, Taiwan; ${ }^{5}$ National Sun Yat-Sen University- \\ Kaohsiung Medical University Joint Research Center, Kaohsiung, Taiwan and ${ }^{6}$ Center for Gene Regulation \\ and Signal Transduction Research, National Cheng Kung University, Tainan, Taiwan
}

\begin{abstract}
Jab1 is a coactivator of AP-1 transcription factor and the fifth subunit of the COP9 signalosome. This protein is a potential oncogene and is involved in the mediation of nuclear exportation and degradation of the tumor suppressor $\mathrm{p} 27^{\mathrm{Kip} 1}$. However, control of Jab1 gene expression and its de-regulation in cancer cells are largely unknown. In this study, we demonstrated that Jab1 is overexpressed in $53(80.3 \%)$ of a series of 66 human breast tumor tissues. In addition, its expression is significantly correlated with HER-2/neu overexpression $(P=0.0318)$. HER-2/neu-overexpressing MDA-MB-453 human breast cancer cells exhibited higher expression of Jab1 than that of MCF-7 breast cancer cells. Promoter activity assay suggested that HER-2/neu oncogene upregulated Jab1 via transcriptional activation. Inhibition of HER-2/neu activity by Herceptin or AG825 significantly attenuated Jab1 expression in HER-2/neu-overexpressing MDA-MB-453 cells. On the contrary, ectopic expression of HER-2/neu stimulated Jab1 expression in MCF-7 cells. Knockdown of Jab1 expression by siRNA resulted in p27 ${ }^{\mathrm{Kip} 1}$ upregulation and G1 growth arrest in Jab1-overexpressing MDA-MB-453 cells. Taken together, our results suggest that Jab1 is a downstream target for HER-2/neu and its overexpression is linked with HER-2/neu expression in breast cancer.
\end{abstract}

Modern Pathology (2008) 21, 609-616; doi:10.1038/modpathol.2008.23; published online 8 February 2008

Keywords: AG825; breast cancer; Herceptin; HER-2/neu; Jab1; p27 $7^{\text {Kip1 }}$

Jab1 was originally identified as a coactivator of AP-1 transcription factor and is an important determiner for the specificity of activation of target genes by AP-1 proteins. ${ }^{1}$ Subsequent studies found that Jab1 is also the fifth component of the COP9/signalosome complex. ${ }^{2,3}$ Recently, a new biological function of Jab1 has been suggested. Tomoda et $a l^{4}$ showed that Jab1 physically interacted with $\mathrm{p} 27^{\mathrm{Kip} 1}$ and enhanced its cytoplasmic translocation which resulted in acceleration of $\mathrm{p} 27^{\mathrm{Kip} 1}$ degradation via the ubiquitin/proteasome pathway. Because $\mathrm{p} 27^{\mathrm{Kip} 1}$ is a typical cyclin-dependent kinase (CDK) inhibitor and a potential tumor suppressor gene, reduction of p27 Kip1 may induce deregulated cell growth. ${ }^{5,6}$ Indeed, downregulation of $\mathrm{p} 27^{\mathrm{Kip} 1}$ protein is

Correspondence: Professor WC Hung, PhD, Institute of Biomedical Sciences, National Sun Yat-Sen University, No. 70, Lien-Hai Road, Kaohsiung 804, Taiwan.

E-mail: hung1228@ms10.hinet.net

Received 23 July 2007; revised and accepted 7 January 2008; published online 8 February 2008 frequently found in human cancers including breast, lung, prostate, gastric, skin, colon and ovarian cancer and is usually correlated with poor clinical outcome..$^{7-13}$ In addition, study of primary tumor tissues also demonstrated that expression of $\mathrm{p} 27^{\mathrm{Kip} 1}$ and Jab1 is inversely correlated in several types of human cancer. ${ }^{14-16}$ However, the mechanism of Jab1 deregulation in cancer cells is largely unknown.

The HER-2/neu oncogene (also known as erbB2) encodes a trans-membrane glycoprotein, which belongs to the human epidermal growth factor receptor family. ${ }^{17,18}$ Amplification and overexpression of HER-2/neu was found in numerous cancers and upregulation of this oncogene was associated with increased metastasis and poor prognosis. Previous studies have uncovered several signaling pathways including the phosphatidylinositol-3-OH kinase (PI-3K)/AKT and the mitogen-activated protein kinase are critical mediators for the oncogenic activity of HER-2/neu. Two recent studies showed that HER-2/neu induces downregulation of p27 ${ }^{\text {Kip } 1}$ via different mechanisms. ${ }^{19,20}$ First, HER-2/neu 
acted through AKT and glycogen synthase kinase- $3 \beta$ to reduce $\mathrm{p} 27^{\mathrm{Kip} 1}$ protein level. Glycogen synthase kinase- $3 \beta$ may phosphorylate cyclin D1 and induce degradation of this protein. Activation of AKT by HER-2/neu inhibits glycogen synthase kinase-3 $\beta$ activity and increases the formation of cyclin D1/ CDK4 complex which may sequester $\mathrm{p} 27^{\mathrm{Kip} 1}$ in the cytoplasm to enhance its turnover. ${ }^{19}$ Second, HER-2/ neu may induce the association of Jab1 and p2 $7^{\text {Kip1 }}$ thereby facilitating nuclear exportation and degradation of $\mathrm{p} 27^{\mathrm{Kip} 1}$ protein. $^{20}$ In this study, we investigated the expression of Jab1 in breast cancer and tested whether Jab1 may be a potential downstream target for HER-2/neu.

\section{Materials and methods}

\section{Immunohistochemical Study}

Paraffin blocks containing formaldehyde-fixed breast cancer tissues of 66 cases were obtained from the Department of Pathology of Chung-Ho Memorial Hospital of Kaohsiung Medical University. Expression of HER-2/neu and Jab1 protein was examined by immunohistochemical staining as described previously. ${ }^{21}$ Both the expression level of proteins and the percentage of positive staining cells were considered. The intensity of Jab1 staining was graded as 0 for negative staining and 1-3 for weak, moderate and strong staining respectively. In addition, we used $50 \%$ as a cutoff to define high vs low Jab1 expression. Same cutoff value has been used to define Jab1 overexpression in laryngeal squamous cell carcinoma and hepatocellular carcinoma. ${ }^{22,23}$ Low and high expressions were scored as 1 and 2 respectively. A final score was calculated by multiplying the intensity score by expression score and the rating (from 0 to 6 ) was determined for each case.

\section{Cell Culture and Plasmids}

MCF-7 and MDA-MB-453 cells were obtained from the cell bank of the National Health Research Institute (Miaoli, Taiwan). Cells were cultured in DMEM/F12 medium containing $10 \%$ charcoalstripped fetal calf serum and antibiotics. Luciferase assay system and pGL3 reporter plasmid were obtained from Promega (Madison, WI, USA). HER2/neu expression vector was kindly provided by Dr Hung MC (MD Anderson Cancer Center, USA). Herceptin was obtained from Genetech Inc. (South San Francisco, CA, USA) and AG825 was purchased from AG Scientific Inc. (San Diego, CA, USA).

\section{Construction of Human Jab1 Promoter-Luciferase Reporter}

The human Jab1 5'-untranslated region was identified by using the BLAST server at the NCBI and the human Jab1 cDNA sequence (accession number NM
006837) as a query. A genomic fragment containing the $5^{\prime}$ upstream region of the Jab1 gene was isolated by PCR amplification from genomic DNA of A549 human lung cancer cells. The primers used are: $5^{\prime}-$ AATGGGGAGGGGTGGTAGTG-3' (forward) and $3^{\prime}$ CTTGCTGCTGTTTCTTGTCG-5' (reverse). The DNA fragment was subcloned into the pGL3 basic reporter plasmid and the nucleotide sequence of the clone was sequenced. The sequence matched perfectly to the $5^{\prime}$ upstream sequence of the human Jab1 cDNA located on chromosome 8 and contained the human Jab1 promoter region (1965 bp upstream of the transcription start site).

\section{Promoter Activity Assay}

Promoter activity of Jab1 gene was analyzed as described previously. ${ }^{24}$.In brief, cells were plated onto 6-well plates at a density of 100000 cells per well and grown overnight. Cells were transfected with $2 \mu \mathrm{g}$ of Jab1 promoter-luciferase constructs and $1 \mu \mathrm{g}$ of CMV- $\beta$-galactosidase plasmid. After transfection, cells were incubated in $10 \%$ fetal calf serum medium containing various drugs for $48 \mathrm{~h}$ and luciferase activity was determined and normalized for $\beta$-galactosidase activity. For some experiments, HER-2/neu expression vector was cotransfected with Jab1 promoter-luciferase construct and promoter activity was assayed at $48 \mathrm{~h}$ after transfection.

\section{RNA Extraction and Reverse Transcription- Polymerase Chain Reaction}

Total RNA was isolated from cells and Jab1 expression was examined by using OneStep RT-PCR kit as described previously. ${ }^{24}$ Glyceraldehyde-3-phosphate dehydrogenase (GAPDH) was used as an internal control to check the efficiency of cDNA synthesis and PCR amplification. cDNA synthesis was performed at $50^{\circ} \mathrm{C}$ for $30 \mathrm{~min}$ and the condition for PCR was 25 cycles of denaturation $\left(94^{\circ} \mathrm{C} / 1 \mathrm{~min}\right)$, annealing $\left(60^{\circ} \mathrm{C} / 1 \mathrm{~min}\right)$, extension $\left(72^{\circ} \mathrm{C} / 1 \mathrm{~min}\right)$ and 1 cycle of final extension $\left(72^{\circ} \mathrm{C} / 10 \mathrm{~min}\right)$. The primers used were: Jab1-forward: $5^{\prime}$-ATGCAGGAAGCGCAG AGT AT-3', Jab1-reverse: 5'-ACCCATCACTTCCAAGTTG C-3', GAPDH-forward, 5'-GAGTCAACGGATTTGGT CGT-3'; and GAPDH-reverse, 5'-TGTGGTCATGAGT CCTTCCA-3'. After reaction, PCR products were separated on a $2 \%$ agarose gel, stained with ethidium bromide and visualized under UV light.

\section{Western Blot Analysis}

After treatments, cells were harvested in a lysis buffer and equal amount of proteins was subjected to SDS-polyacrylamide gel electrophoresis as described previously. ${ }^{24}$.Proteins were transferred to nitrocellulose membranes and the membranes were probed with different primary antibodies. Enhanced 
chemiluminescence reagents were used to depict the protein bands on the blots. Jab1, antibody was obtained from Santa Cruz (Santa Cruz, CA, USA) and anti-HER-2/neu antibody was from Calbiochem (Cambridge, MA, USA). Anti-actin antibody was obtained from Chemicon (Temecula, CA, USA).

\section{siRNA Treatment and Cell Growth Assay}

Jab1 small interfering RNA (siRNA) 5'-GAGUUU GUUCCCGUGGUGCUU-3' (sense strand) and a nonspecific RNA 5'-GCACCACGGGAACAAACUCUU- ${ }^{\prime}$ (sense strand) were synthesized (Dharmacon Research Inc. Huston, TX, USA). MDA-MB-453 and MCF-7 cells were transfected with control or Jab1 siRNA by using the LipofectAMINE reagent. Cells were received a second transfection after $12 \mathrm{~h}$ and maintained in $10 \%$ fetal calf serum medium for another $60 \mathrm{~h}$. Effect of siRNA on cell cycle-distribution was studied by flow cytometry as described previously. ${ }^{25}$

\section{Preparation of Subcellular Fractions}

To study the subcompartmental differences, MDAMB-453 cells transfected with control or Jab1 siRNA were harvested at $48 \mathrm{~h}$ after transfection. Cells were lysed in buffer A (10 mM 4-(2-hydroxyethyl)1-piperazineethanesulfonic acid, $1.5 \mathrm{mM} \mathrm{MgCl}_{2}$, $10 \mathrm{mM} \mathrm{KCl}, 300 \mathrm{mM}$ sucrose, $0.5 \% \mathrm{NP}-40,1 \mathrm{mM}$ dithiothretol, pH7.9) with proteinase inhibitors for 10 min on ice. Nuclei were harvested by centrifugation and supernatants (cytoplasmic fractions) were collected. Nuclear pellet were resuspended in Buffer B (20 mM 4-(2-hydroxyethyl)-1-piperazineethanesulfonic acid, $1.5 \mathrm{mM} \mathrm{MgCl}_{2}, 420 \mathrm{mM} \mathrm{NaCl}, 0.2 \mathrm{mM}$ ethylenediaminetetraacetic acid, $20 \%$ glycerol, $1 \mathrm{~mm}$ dithiothretol, pH7.9) with proteinase inhibitors for $30 \mathrm{~min}$ on ice for extraction of nuclear proteins. Nuclear extracts were diluted with equal volume of buffer D (20 mM 4-(2-hydroxyethyl)-1piperazineethanesulfonic acid, $10 \mathrm{mM} \mathrm{KCl}, 0.2 \mathrm{mM}$ ethylenediaminetetraacetic acid, 25\% glycerol, $1 \mathrm{mM}$ dithiothretol, pH7.9) and subjected to centrifugation to remove debris. The supernatants were collected as the nuclear fractions.

\section{Statistical Analysis}

The association between the expression of Jab1 and HER-2/neu or other tumor characteristics was assessed using $\chi^{2}$ or Fisher's exact test. Statistical significance was defined as $P<0.05$.

\section{Results}

\section{HER-2/neu and Jab1 were Coexpressed in Human Breast Cancer Tissues}

We first examined the expression of Jab1 in human breast tumor tissues. Our results showed that positive Jab1 staining was detected predominantly in the nucleus. However, some positive signals were also observed in the cytoplasm. Overexpression of Jab1 was found in $53(80.3 \%)$ of a series of 66 human breast tumor tissues. We next studied the association between Jab1 and clincopathological characteristics. Jab1 protein level in breast cancer tissues with low HER-2/neu expression (score 0-1) was very low (Figure 1a). In contrast, high protein level of Jab1 was detected in tumor tissues with HER-2/neu overexpression (score 3) (Figure 1b). Statistical analysis clearly demonstrated a positive correlation between HER-2/neu and Jab1 expression in breast tumor tissues $(P=0.0318$, Table 1$)$. Our data also showed that Jab1 expression was not associated with histological grade and stage (Table 2). However, a marginal correlation between Jab1 and estrogen receptor or progesterone receptor was found.

\section{HER-2/neu Upregulated Jab1 via Transcriptional Activation in Human Breast Cancer Cells}

We next studied whether Jab1 is a downstream target for HER-2/neu in human breast cancer cells. As shown in Figure 2a, MDA-MB-453 breast cancer cells, which exhibited HER-2/neu overexpression expressed higher Jab1 mRNA level than that of MCF7 cells, which expressed low level of HER-2/neu. The Jab1 promoter activity was also higher in MDAMB-453 cells (Figure 2b). These data suggested that HER-2/neu might directly upregulate Jab1 via transcriptional activation in breast cancer cells. To verify this issue, we ectopically expressed constitutively active HER-2/neu oncogene in MCF-7 cells and investigated Jab1 expression in these cells. We found that Jab1 promoter activity and mRNA were increased by HER-2/neu (Figure $3 a$ and b). In consistent with these data, Jab1 protein level was also increased in MCF-7 transfected with HER-2/neu expression vector (Figure 3c). Our results suggested that Jab1 is a downstream target for HER-2/neu in human breast cancer cells.

\section{Inhibition of HER-2/neu Attenuated Jab1 Expression in Human Breast Cancer Cells}

To further confirm the functional role of HER-2/neu on the regulation of Jab1, we investigated the effect of the anti-HER-2/neu antibody Herceptin and the selective HER-2/neu kinase inhibitor AG825 on the expression of Jab1 in HER-2/neu- overexpressing MDA-MB-453 cells. Our results clearly demonstrated that Herceptin and AG825 inhibited Jab1 promoter activity (Figure 4a) and mRNA expression (Figure 4b) in MDA-MB-453 cells. Similarly, Jab1 protein level was also attenuated by these two drugs. These results indicated that HER-2/neu functions as an upstream regulator for Jab1 in human breast cancer cells. 

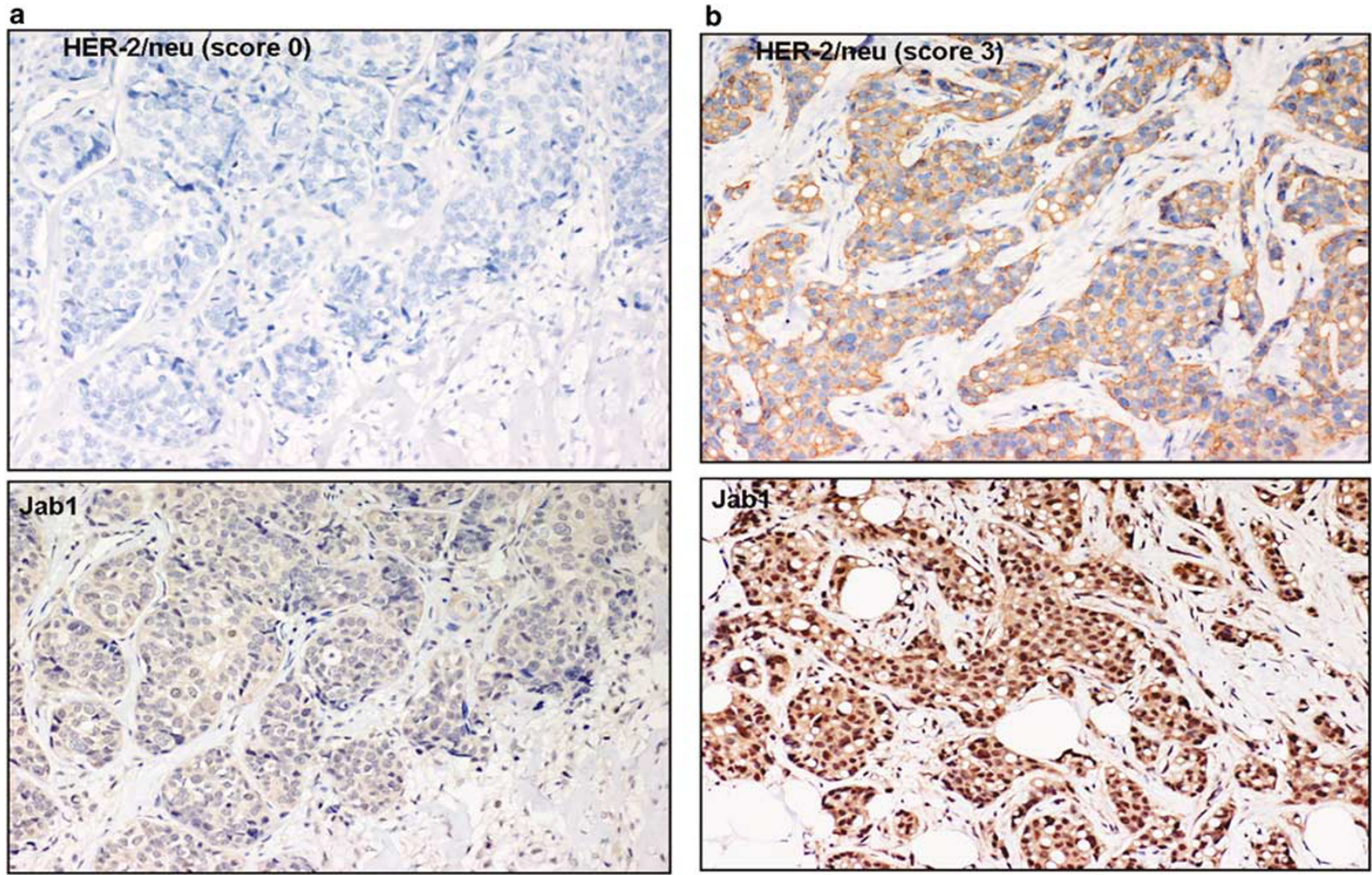

Figure 1 Correlation of the expression of HER-2/neu and Jab1 in human breast tumor tissues. (a) Weak immunostaining of Jab1 (intensity score 1) in a tumor tissue with no HER-2/neu overexpression (intensity score 0). (b) Strong immunostaining of Jab1 (intensity score 3) in a tumor tissue with strong HER-2/neu expression (intensity score 3).

Table 1 Correlation between the expression of HER-2/neu and Jab1 in breast cancer tissues

\begin{tabular}{lcccc}
\hline \multirow{2}{*}{$\begin{array}{l}\text { HER-2/neu } \\
\text { expression }\end{array}$} & $\begin{array}{c}\text { Case } \\
\text { number }\end{array}$ & \multicolumn{3}{c}{ Jab1 expression $^{\mathrm{a}}$} \\
\cline { 3 - 5 } & & $\begin{array}{c}\text { Score }<4 \\
(\%)\end{array}$ & $\begin{array}{c}\text { Score } \geq 4 \\
(\%)\end{array}$ \\
\hline $0-1$ & 34 & $10(29.4)$ & $24(70.6)$ & \\
3 & 32 & $3(9.4)$ & $29(90.6)$ & $P=0.0318$
\end{tabular}

${ }^{\mathrm{a}}$ The intensity of Jab 1 staining was graded as 0 for negative staining and 1-3 for weak, moderate and strong staining respectively. Low and high expressions were scored as 1 and 2 respectively. A final score was calculated by multiplying the intensity score by expression score and the rating (from 0 to 6 ) was determined.

\section{Knockdown of Jab1 Induced p27 ${ }^{\mathrm{Kip} 1}$ Upregulation and G1 Growth Arrest in HER-2/neu-overexpressing MDA-MB-453 Cells}

To address the importance of Jab1 in HER-2/neuinduced cell growth, we suppressed the expression of Jab1 in MDA-MB-453 by siRNA and examined its effect on cell growth. Our results showed that our designed siRNA effectively downregulated Jab1 protein level in MDA-MB-453 and MCF-7 cells (Figure 5a). As shown in Figure 5 b, about $50 \%$ of MDA-MB-453 cells treated with nonspecific RNA were at the G1 phase. The percentage of cells at G1
Table 2 Correlation between Jab1 expression and tumor characteristics

\begin{tabular}{|c|c|c|c|c|}
\hline \multirow{2}{*}{$\begin{array}{l}\text { Tumor } \\
\text { characteristics }\end{array}$} & \multirow{2}{*}{$\begin{array}{c}\text { Case } \\
\text { number }\end{array}$} & \multicolumn{3}{|c|}{ Jab1 expression ${ }^{\mathrm{a}}$} \\
\hline & & $\begin{array}{c}\text { Score }<4 \\
(\%)\end{array}$ & $\begin{array}{c}\text { Score }>4 \\
(\%)\end{array}$ & \\
\hline \multicolumn{5}{|c|}{ Histological grade } \\
\hline I-II & 41 & 8 & 33 & $P=0.248$ \\
\hline III-IV & 25 & 5 & 20 & \\
\hline \multicolumn{5}{|l|}{ Stage } \\
\hline I-I & 44 & 7 & 37 & $P=0.140$ \\
\hline III-IV & 22 & 6 & 16 & \\
\hline \multicolumn{5}{|c|}{ Estrogen receptor } \\
\hline- & 26 & 8 & 18 & $P=0.068$ \\
\hline+ & 40 & 5 & 35 & \\
\hline \multicolumn{5}{|c|}{ Progesterone receptor } \\
\hline - & 26 & 8 & 18 & $P=0.068$ \\
\hline+ & 40 & 5 & 35 & \\
\hline
\end{tabular}

${ }^{\mathrm{a}}$ Jab1 expression was scored as described in Table 1.

phase was increased to $70 \%$ and cells at S phase were reduced to about $12 \%$. On the contrary, only very minor change of cell cycle distribution was observed in MCF-7 cells treated with Jab1 siRNA because these cells expressed low level of Jab1. 
a

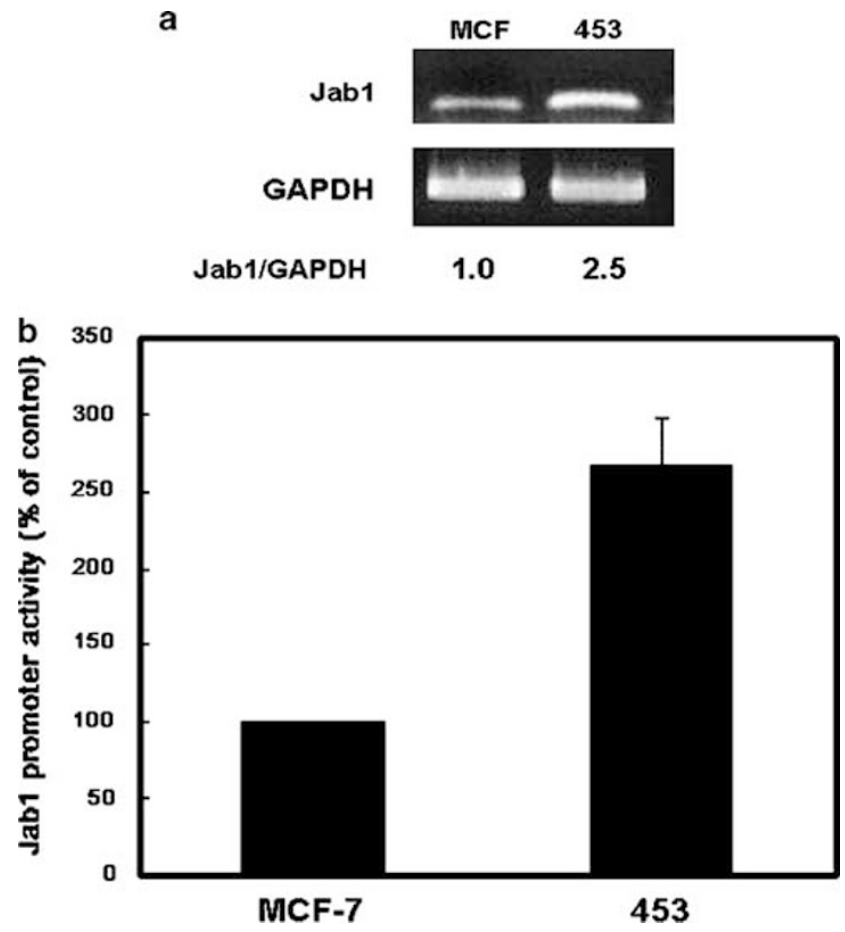

Figure 2 Increase of Jab1 expression in HER-2/neu-overexpressing human breast cancer cells. (a) MCF-7 (MCF) and MDA-MB453 (453) human breast cancer cells cultured in $10 \%$ fetal calf serum medium. Total RNA was also extracted from these cell lines and expression of Jab1 was investigated by RT-PCR. The ratio of Jab1/GAPDH of MCF-7 cells was defined as 1. (b) Jab1 promoterluciferase construct was transfected into these two cell lines and luciferase activity was assayed at $48 \mathrm{~h}$ after transfection. Luciferase activity of MCF-7 cell was defined as $100 \%$.

Our immunohistochemical study revealed that Jab1 staining was detected both in nucleus and cytoplasm. Therefore, we studied the effect of Jab1 siRNA on the expression of Jab1 and p27 $7^{\text {Kip1 }}$ in nucleus and cytoplasm. The purity of nuclear and cytoplasmic proteins extracted was good because the nuclear fraction contained enriched nuclear marker cyclin-dependent kinase 6 while the cytoplasmic fraction had enriched cytoskeleton actin (Figure 5c). We found that Jab1 siRNA caused reduction of nuclear Jab1. Importantly, the nuclear level of $\mathrm{p} 27^{\mathrm{Kip} 1}$ was significantly increased after knockdown of Jab1. The increase of nuclear p27 $7^{\text {Kip1 }}$ correlated with its biological activity, which might form a complex with cyclin/CDK and induce G1 growth arrest (as found in Figure 5b). Similarly, the cytoplasmic Jab1 was also reduced by this specific siRNA. Downregulation of Jab1 attenuated its ability to induce nuclear exportation of $\mathrm{p} 27^{\mathrm{Kip} 1}$. Indeed, our data showed that cytoplasmic $\mathrm{p} 27^{\mathrm{Kip} 1}$ was reduced. As shown in Figure 6c, the cytoplasmic p2 $7^{\text {Kip1 }}$ level was much higher than that of nuclear $\mathrm{p} 27^{\mathrm{Kip} 1}$ in control siRNA-treated MDA-MB-453 cells. On the contrary, the cytoplasmic and nuclear levels of p27 $7^{\text {Kip1 }}$ were reversed by Jab1 siRNA. So, the cytoplasmic Jab1 expression is of functional consequence. Collectively, we found that knockdown of

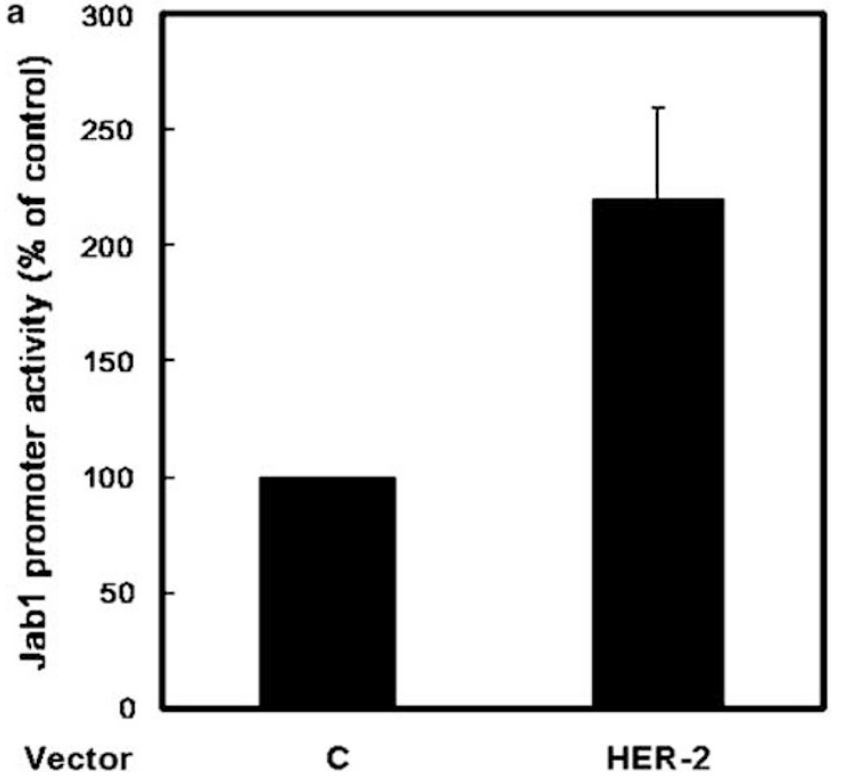

b

Jab1

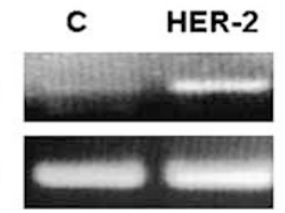

c

C HER-2

Jab1

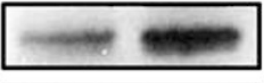

GAPDH

Actin

Figure 3 HER-2/neu upregulates Jab1 expression in human breast cancer cells. (a) MCF-7 cells were cotransfected with Jab1 promoter luciferase reporter and control (c) or HER-2/neu expression vector (HER-2). After $48 \mathrm{~h}$, promoter activity was assayed. The luciferase activity of cells transfected with control vector was defined as $100 \%$. (b) The Jab1 mRNA level in cells transfected with control (c) or HER-2/neu (HER-2) expression vector was also investigated by RT-PCR and GAPDH was used as internal control. (c) The Jab1 protein level in cells transfected with control (c) or HER-2/neu (HER-2) expression vector was also investigated by western blotting.

Jab1 preferentially inhibited the progression of Jab1overexpressing MDA-MB-453 cells.

\section{Discussion}

Recent studies suggest that Jab1 is a potential oncogene and may play critical roles in tumorigenesis. Jab1 has been shown to induce p2 ${ }^{\text {Kip1 }}$ nuclear exportation and degradation to promote cell proliferation. ${ }^{4}$ Jab1 may trigger the proteolysis of the tumor suppressor p53 and exhibit tumor-promoting activity in cells. ${ }^{26}$ In addition, Jab1 interacts directly with Smad4 and induces its degradation via the ubiquitin/ proteasome pathway which leads to attenuation of transforming growth factor- $\beta$-induced gene transcription. ${ }^{27}$ Because transforming growth factor- $\beta$ exhibits anti-cancer activity in the early stages of tumorigenesis, inhibition of transforming growth factor- $\beta$ signaling pathway by Jab1 may promote tumor formation. Jab1 also binds hypoxia inducible factor-1, prevents its degradation and enhances its transcriptional activity. ${ }^{28}$ Upregulation 

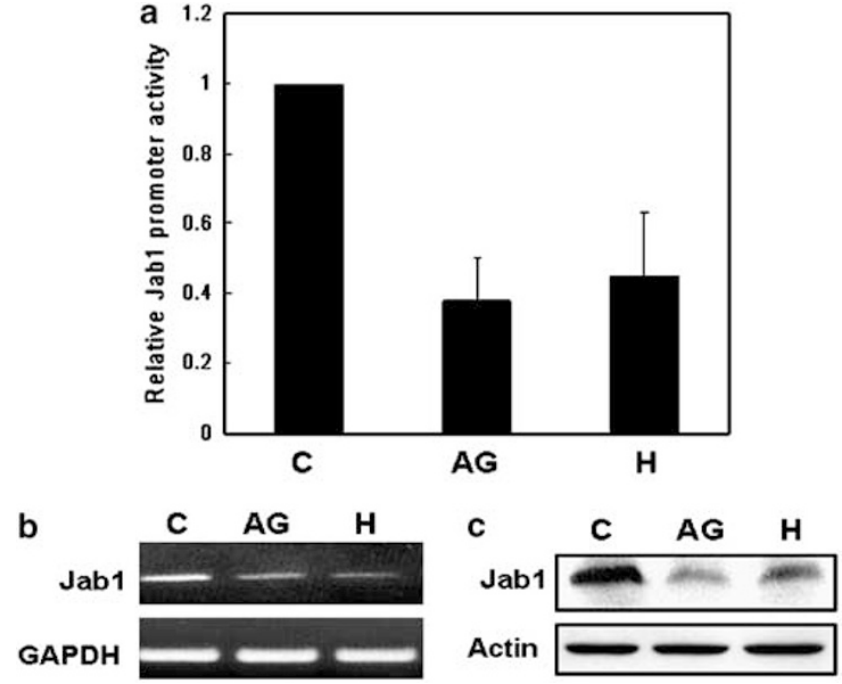

Figure 4 Inhibition of HER-2/neu activity attenuated Jab1 expression in HER-2/neu-overexpressing MDA-MB-453 cells. (a) MDA-MB-453 cells were transfected with Jab1 promoter-luciferase reporter plasmid and treated with $0.05 \%$ DMSO (c), AG825 (AG $50 \mu \mathrm{M})$ or Herceptin $(\mathrm{H}, 20 \mu \mathrm{g} / \mathrm{ml}$ ). Promoter activity was assayed at $48 \mathrm{~h}$ after transfection. The luciferase activity of cells treated with $0.05 \%$ DMSO was defined as 1 . (b) The Jab1 mRNA level in cells treated with drugs was investigated by RT-PCR and GAPDH was used as internal control. (c) The Jab1 protein level in cells treated with drugs was also investigated by western blotting.

of hypoxia inducible factor-1 by Jab1 in turn stimulates the expression of vascular endothelial growth factor, a major hypoxia inducible factor-1 target, to enhance tumor angiogenesis. These data suggest that Jab1 is a tumor promoter. Indeed, inhibition of Jab1 expression reduced cell growth of several types of human cancer. ${ }^{29-31}$

However, the mechanisms that enhance Jab1 overexpression in cancer cells are unclear. A previous study demonstrated that Jab1 overexpression in human hepatocelular carcinoma tissues is due to increase of gene copy number. So, gene amplification is one of the mechanisms that cause Jab1 deregulation in cancer. In this study, we find that Jab1 is a downstream target of HER-2/neu oncogene and is upregulated via enhancement of gene transcription in human breast cancer. Several evidences support this conclusion. First, pathological investigation indicated that Jab1 expression is strongly associated with HER-2/neu overexpression. In contrast to our results, Esteva et $a l^{32}$ reported that no correlation is detected between expression of HER-2/neu and Jab1. The discrepancy may be due to the scoring method. In their study, Esteva et $a l^{32}$ observed both cytoplasmic and nuclear stating of Jab1. However, they only focused on nuclear Jab1 and showed that HER-2/neu expression is not a

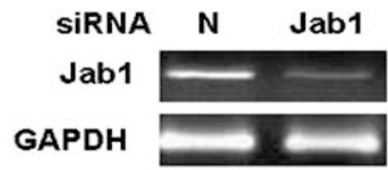

MCF

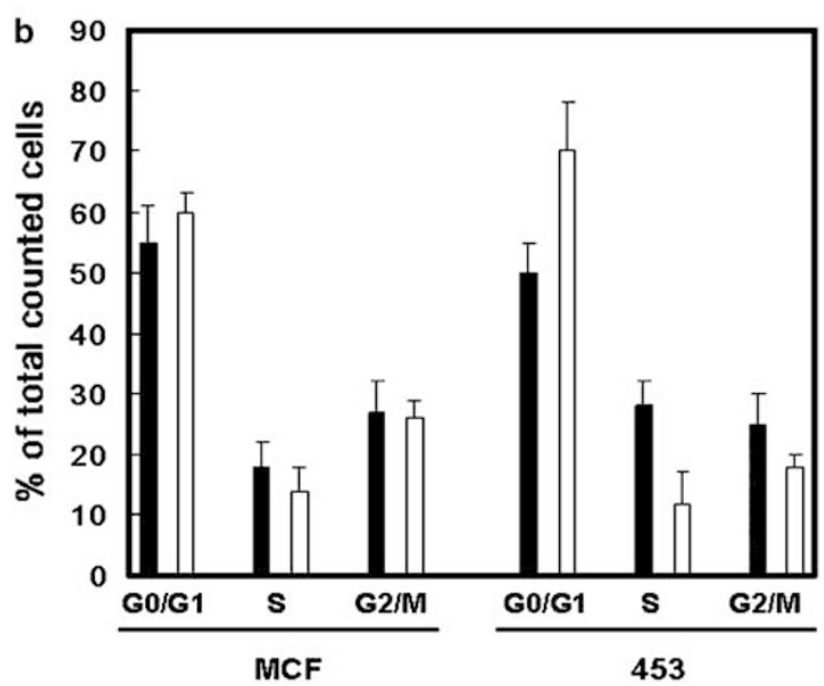

C Total cellular protein
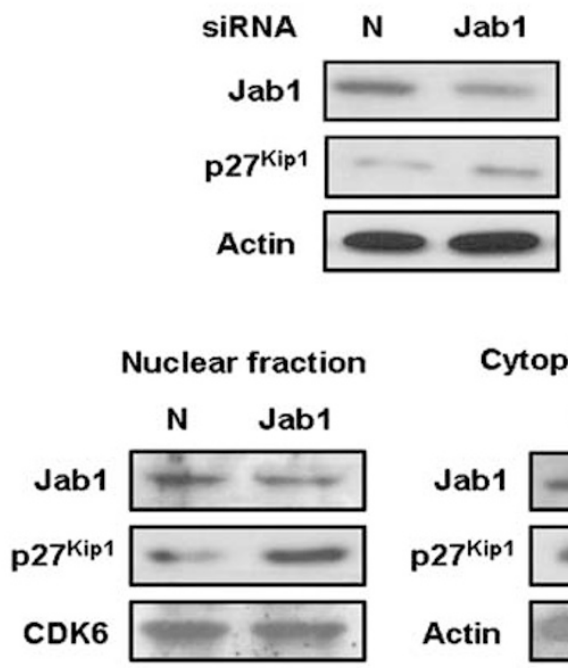

Cytoplasmic fraction

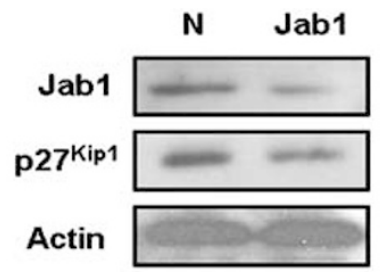

Figure 5 Inhibition of cell-cycle progression by Jab1 siRNA. (a) MDA-MB-453 and MCF-7 cells were transfected with nonspecific (N) or Jab1 siRNA as described in the Materials and Methods. Total RNA was isolated and Jab1 expression was investigated by RT-PCR. (b) Cells treated with nonspecific RNA ( $\square$, black bar) or Jab1 siRNA ( $\square$, white bar) were also harvested for analysis of cell-cycle distribution by flow cytometry. The percentages of cells at different phases were expressed Mean \pm s.d. (c) Total cellular proteins or nuclear and cytoplasmic fractions of cells transfected with nonspecific (N) or Jab1 siRNA were prepared and the protein level of Jab1 and p27 ${ }^{\text {Kip } 1}$ was assessed by western blot analysis. Cyclin-dependent kinase 6 and actin were used as marker proteins for the identification of protein purification. 
associated with nuclear Jab1. On the contrary, we scored the intensity and the number of cancer cells with positive staining in the nucleus and cytoplasm. In fact, Jab1 exhibits important biological activity in both subcellular locations. Jab1 in the nucleus functions as transcription coactivator and may interact and modulate the activity of steroid receptors as demonstrated previously. ${ }^{33,34}$ Our results indeed demonstrated a marginal correlation between Jab1 and estrogen receptor or progesterone receptor (Table 2). The functional interaction between steroid receptors and Jab1 received much attention recently. Chauchereau et $a l^{34}$ firstly reported that Jab1 interacted with progesterone receptor and its coactivator SRC-1 which resulted in stabilization of the progesterone receptor/SRC-1 complex. Subsequently, Callige et $a l^{33}$ showed that Jab1 was involved in ligand-dependent degradation of estrogen receptor by the proteasome. These data suggested that Jab1 might modulate the transcriptional activity of steroid receptors. Although the biological importance of the interaction between Jab1 and steroid receptors (especially estrogen receptor) in vivo is still unclear, elucidation of this interaction may contribute to the understanding of breast tumorigenesis and provide new strategies for cancer treatment. In cytoplasm, Jab1 may function as signal transducer, which can modulate various signaling pathways. Thus, we think both nuclear and cytoplasmic Jab1 should be considered in pathological analysis. Otherwise, some important correlations may be missed. Second, in vitro transfection assay showed that HER-2/neu directly activated Jab1 promoter activity and mRNA expression in MCF-7 cells. Conversely, inhibition of HER2/neu by Herceptin or AG825 significantly downregulated Jab1 promoter activity and mRNA expression in MDA-MB-453 cells. Similar results had been observed by Le et $a l^{35}$ who demonstrated that Herceptin inhibited Jab1 expression in different types of cancer cells. Third, knockdown of Jab1 induced $\mathrm{p} 27^{\mathrm{Kip} 1}$ upregulation and G1 growth arrest in MDA-MB-453 cells.

Taken together, these results suggest that Jab1 may be one of the critical mediators for HER-2/neu to promote tumorigenesis via modulation of multiple intracellular signaling pathways and Jab1 may be a rational target for cancer therapy.

\section{Acknowledgement}

This study was supported by Grant NSC-96-2320-B110-001 of the National Science Council, Republic of China. This study was also supported by the grants from Center for Gene Regulation and Signal Transduction Research of National Cheng Kung University and National Sun Yat-Sen UniversityKaohsiung Medical University Joint Research Center.

\section{Disclosure/conflict of Interest}

The authors declare no conflicts of interest.

\section{References}

1 Claret FX, Hibi M, Dhut S, et al. A new group of conserved coactivators that increase the specificity of AP-1 transcription factors. Nature 1996;383:453-457.

2 Seeger M, Kraft R, Ferrell K, et al. A novel protein complex involved in signal transduction possessing similarities to $26 \mathrm{~S}$ proteasome subunits. FASEB J 1998;12:469-478.

3 Wei N, Tsuge T, Serino G, et al. The COP9 complex is conserved between plants and mammals and is related to the $26 \mathrm{~S}$ proteasome regulatory complex. Curr Biol 1998;8:919-922.

4 Tomoda K, Kubota Y, Kato J. Degradation of the cyclindependent-kinase inhibitor p27Kip1 is instigated by Jab1. Nature 1999;398:160-165.

5 Polyak K, Lee MH, Erdjument-Bromage $\mathrm{H}$, et al. Cloning of p27Kip1, a cyclin-dependent kinase inhibitor and a potential mediator of extracellular antimitogenic signals. Cell 1994;78:59-66.

6 Toyoshima H, Hunter T. p27, a novel inhibitor of G1 cyclin-Cdk protein kinase activity, is related to p21. Cell 1994;78:67-74.

7 Porter PL, Malone KE, Heagerty PJ, et al. Expression of cell-cycle regulators p27Kip1 and cyclin E, alone and in combination, correlate with survival in young breast cancer patients. Nat Med 1997;3:222-225.

8 Esposito V, Baldi A, De Luca A, et al. Prognostic role of the cyclin- dependent kinase inhibitor p27 in nonsmall cell lung cancer. Cancer Res 1997;57:3381-3385.

9 Tsihlias J, Kapusta LR, DeBoer G, et al. Loss of cyclin-dependent kinase inhibitor p27Kip1 is a novel prognostic factor in localized human prostate adenocarcinoma. Cancer Res 1998;58:542-548.

10 Ohtani $\mathrm{M}$, Isozaki $\mathrm{H}$, Fujii $\mathrm{K}$, et al. Impact of the expression of cyclin- dependent kinase inhibitor p27Kip1 and apoptosis in tumor cells on the overall survival of patients with non-early stage gastric carcinoma. Cancer 1999;85:1711-1718.

11 Florenes VA, Maelandsmo GM, Kerbel RS, et al. Protein expression of the cell-cycle inhibitor p27Kip1 in malignant melanoma: inverse correlation with disease-free survival. Am J Pathol 1998;153:305-312.

12 Ciaparrone M, Yamamoto H, Yao Y, et al. Localization and expression of p27KIP1 in multistage colorectal carcinogenesis. Cancer Res 1998;58:114-122.

13 Newcomb EW, Sosnow M, Demopoulos RI, et al. Expression of the cell cycle inhibitor p27KIP1 is a new prognostic marker associated with survival in epithelial ovarian tumors. Am J Pathol 1999;154: 119-125.

14 Shen L, Tsuchida R, Miyauchi J, et al. Differentiationassociated expression and intracellular localization of cyclin-dependent kinase inhibitor p27KIP1 and c-Jun co-activator JAB1 in neuroblastoma. Int J Oncol 2000; 17:749-754.

15 Sui L, Dong Y, Ohno M, et al. Jab1 expression is associated with inverse expression of p27(kip1) and poor prognosis in epithelial ovarian tumors. Clin Cancer Res 2001;7:4130-4135. 
16 Kouvaraki MA, Rassidakis GZ, Tian L, et al. Jun activation domain-binding protein 1 expression in breast cancer inversely correlates with the cell cycle inhibitor p27(Kip1). Cancer Res 2003;63:2977-2981.

17 Schechter AL, Stern DF, Vaidyanathan L, et al. The neu oncogene: an erb-B- related gene encoding a $185000-$ Mr tumour antigen. Nature 1984;312:513-516.

18 Schechter AL, Hung MC, Vaidyanathan L, et al. The neu gene: an erbB- homologous gene distinct from and unlinked to the gene encoding the EGF receptor. Science 1985;229:976-978.

19 Yang HY, Zhou BP, Hung MC, et al. Oncogenic signals of HER-2/neu in regulating the stability of the cyclindependent kinase inhibitor p27. J Biol Chem 2000;275: 24735-24739.

20 Lenferink AEG, Busse D, Flanagan WM, et al. ErbB2/ neu kinase modulates cellular p27(Kip1) and cyclin D1 through multiple signaling pathways. Cancer Res 2001;61:6583-6591.

21 Tsai KB, Hou MF, Lin HJ, et al. Expression of HER-2/ NEU oncoprotein in familial and non-familial breast cancer. Kaohsiung J Med Sci 2001;17:64-76.

22 Dong Y, Sui L, Watanabe Y, et al. Prognostic significance of Jab1 expression in laryngeal squamous cell carcinomas. Clin Cancer Res 2005;11:259-266.

23 Patil MA, Gutgemann I, Zhang J, et al. Array-based comparative genomic hybridization reveals recurrent chromosomal aberrations and Jab1 as a potential target for $8 \mathrm{q}$ gain in hepatocellular carcinoma. Carcinogenesis 2005;26:2050-2057.

24 Hsu MC, Chang HC, Hung WC. HER-2/neu represses the metastasis suppressor RECK via ERK and Sp transcription factors to promote cell invasion. J Biol Chem 2006;281:4718-4725.

25 Lee TH, Chuang LY, Hung WC. Induction of p21WAF1 expression via Sp1-binding sites by tamoxifen in estrogen receptor-negative lung cancer cells. Oncogene 2000;19:3766-3773.
26 Bech-Otschir D, Kraft R, Huang X, et al. COP9 signalosome-specific phosphorylation targets p53 to degradation by the ubiquitin system. EMBO J 2001;20:1630-1639.

27 Wan M, Cao X, Wu Y, et al. Jab1 antagonizes TGF-beta signaling by inducing Smad4 degradation. EMBO Rep 2002;3:171-176.

28 Bae MK, Ahn MY, Jeong JW, et al. Jab1 interacts directly with HIF-1alpha and regulates its stability. J Biol Chem 2002;277:9-12.

29 Tomoda K, Kato JY, Tatsumi E, et al. The Jab1/COP9 signalosome subcomplex is a downstream mediator of Bcr-Abl kinase activity and facilitates cell-cycle progression. Blood 2005;105:775-783.

30 Kouvaraki MA, Korapati AL, Rassidakis GZ, et al. Potential role of Jun activation domain-binding protein 1 as a negative regulator of p27kip1 in pancreatic adenocarcinoma. Cancer Res 2006;66: 8581-8589.

31 Fukomoto A, Tomoda K, Yoneda-Kato $\mathrm{N}$, et al. Depletion of Jab1 inhibits proliferation of pancreatic cancer cell lines. FEBS Lett 2006;580:5836-5840.

32 Esteva FJ, Sahin AA, Rassidakis GZ, et al. Jun activation domain binding protein 1 expression is associated with low p27(Kip1) levels in nodenegative breast cancer. Clin Cancer Res 2003;9: 5652-5659.

33 Callige M, Kieffer I, Richard-Foy H. CSN5/Jab1 is involved in ligand- dependent degradation of estrogen receptor \{alpha\} by the proteasome. Mol Cell Biol 2005;25:4349-4358.

34 Chauchereau A, Georgiakaki M, Perrin-Wolff M, et al. JAB1 interacts with both the progesterone receptor and SRC-1. J Biol Chem 2000;275:8540-8548.

35 Le XF, Pruefer F, Bast Jr RC. HER2-targeting antibodies modulate the cyclin- dependent kinase inhibitor p27Kip1 via multiple signaling pathways. Cell Cycle 2005;4:87-95. 